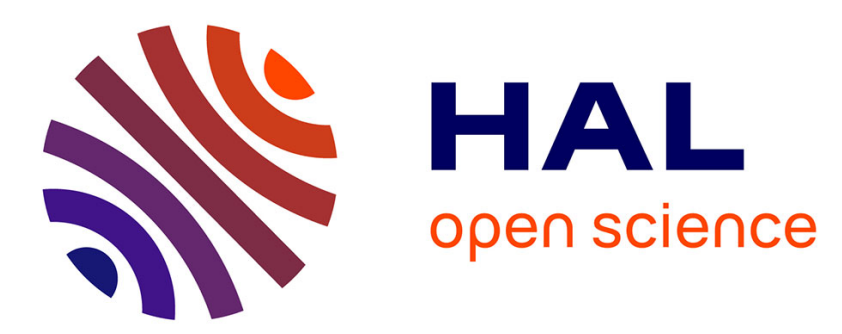

\title{
Assessment of the Physico-Chemical Properties of Waste Cooking Oil and Spent Coffee Grounds Oil for Potential Use as Asphalt Binder Rejuvenators
}

Rita Jalkh, Houssam El-Rassy, Ghassan R Chehab, Mohamad G Abiad

\section{- To cite this version:}

Rita Jalkh, Houssam El-Rassy, Ghassan R Chehab, Mohamad G Abiad. Assessment of the PhysicoChemical Properties of Waste Cooking Oil and Spent Coffee Grounds Oil for Potential Use as Asphalt Binder Rejuvenators. Waste and Biomass Valorization, 2018, 9 (11), pp.2125-2132. 10.1007/s12649017-9984-z . hal-03137555

\section{HAL Id: hal-03137555 \\ https://hal.science/hal-03137555}

Submitted on 5 Mar 2021

HAL is a multi-disciplinary open access archive for the deposit and dissemination of scientific research documents, whether they are published or not. The documents may come from teaching and research institutions in France or abroad, or from public or private research centers.
L'archive ouverte pluridisciplinaire HAL, est destinée au dépôt et à la diffusion de documents scientifiques de niveau recherche, publiés ou non, émanant des établissements d'enseignement et de recherche français ou étrangers, des laboratoires publics ou privés. 


\section{Assessment of the Physico-chemical Properties of Waste Cooking Oil and Spent Coffee Grounds Oil for Potential Use as Asphalt Binder Rejuvenators}

Rita Jalkh ${ }^{1}$, Houssam El-Rassy ${ }^{2}$, Ghassan R. Chehab ${ }^{3}$ and Mohamad G. Abiad ${ }^{1, *}$

${ }^{1}$ Department of Nutrition and Food Sciences, Faculty of Agricultural and Food Sciences, American University of Beirut, P.O. Box 11-0236 Riad El Solh, Beirut 1107-2020, Lebanon

${ }^{2}$ Department of Chemistry, Faculty of Arts and Sciences, American University of Beirut, P.O. Box 11-0236 Riad El Solh, Beirut 1107-2020, Lebanon

${ }^{3}$ Department of Civil and Environmental Engineering, Faculty of Engineering and Architecture, American University of Beirut, P.O. Box 11-0236 Riad El Solh, Beirut 1107-2020, Lebanon

*Corresponding author:

Mohamad G. Abiad

Tel.: +961-1-350000 ext. 4412.

Email address: ma192@aub.edu.lb

The final publication is available at Springer Nature via https://doi.org/10.1007/s12649-017-9984-z 


\begin{abstract}
Recycling of waste is an optional approach across industries to reduce environmental harm and turn it into sustainable and valuable resource alternatives. This paper addresses recycling of food industry waste through exploring potential use to enhance damaged asphalt binder used in roadways. The two wastes, spent coffee grounds (SCG) and waste cooking oil (WCO) were subjected to different levels of oxidation after which their physical and chemical properties were analyzed. Results show that oxidation significantly affects the oils by increasing the release of fatty acids and breaking of double bonds. The latter, in addition to polymerization and release of high molecular weight compounds, increases the viscosities of the oils while retaining their Newtonian behavior. As such, oxidation may be able to effectively customize physicochemical properties of oils, namely viscosity, for their reported application as asphalt binder rejuvenators. The rejuvenated binder can then be reused in production of asphalt for low traffic roadways.
\end{abstract}

Keywords: Recycling; Asphalt; Binder; Aging Oxidation; Rheology; Viscoelasticity 


\section{Introduction}

Increased environmental awareness combined with an ever-growing concern of depleting natural resources have encouraged researchers to explore new methods to reduce waste generation, recycle and reuse material and by-products of the various industries. Waste Cooking Oil (WCO), comprising of residual oils generated from households as well as the food industry, and Spent Coffee Grounds (SCG), a waste generated by coffee brewing, are two types of food wastes present in large quantities and pose environmental concerns. According to Li and Wang (2015), more than 18 million tons of WCO are produced annually worldwide in addition to 8.8 million tons of coffee traded annually as reported by the International Coffee Organization (ICO, 2015).

Waste cooking oil is considered to have detrimental effects on the environment mainly by altering oxygen levels of water due to the formation on an impermeable layer that covers the surface. Moreover, during the degradation of WCO toxic compounds are released which may be ingested by aquatic animals and thus get transmitted back into the human food chain (Kabir, Yacob, \& Radam, 2014). Similarly, it has been reported that during decomposition, SCG requires high oxygen demand whilst it releases organic matter along with other contaminants such as caffeine, tannins and polyphenols into the environment (Mussatto, Machado, Martins, \& Teixeira, 2011).

For these reasons and in attempts to reduce the dependency on fossil fuels and abate competition with oils from food sources, numerous studies have focused on the recycling and reuse of waste vegetable oils in various applications including the production of biodiesel, biochar as well as lubricants (Al-Hamamre, Foerster, Hartmann, Kröger, \& Kaltschmitt, 2012; Kulkarni \& Dalai, 2006; Li \& Wang, 2015; Phimsen et al., 2016; Vardon et al., 2013; Yaakob, 
Mohammad, Alherbawi, Alam, \& Sopian, 2013). On the other hand, several options to reduce the environmental impact of SCG have been explored (Mussatto, Machado, et al., 2011). As alternative to landfills, SCG has been used in animal feed (Givens \& Barber, 1986), the production of organic compost or as fertilizer (Adi \& Noor, 2009; Liu \& Price, 2011; Vardon et al., 2013), anaerobic digestion (Dinsdale, Hawkes, \& Hawkes, 1996), or even as solid fuel (Kondamudi, Mohapatra, \& Misra, 2008). Other applications also include the use of SCG as absorbents to remove heavy metals (Lavecchia, Pugliese, \& Zuorro, 2010) and cationic dyes (A. S. Franca, Oliveira, Mendonca, \& Silva, 2005; Adriana S. Franca, Oliveira, Mendonça, \& Silva, 2005). This in addition to the extraction of high value compounds (Panusa, Zuorro, Lavecchia, Marrosu, \& Petrucci, 2013), feedstock for the production of activated carbon (Kante, NietoDelgado, Rangel-Mendez, \& Bandosz, 2012), bioethanol and biodiesel production (Nídia S Caetano, Silva, Melo, Martins, \& Mata, 2014; Mussatto, Machado, Carneiro, \& Teixeira, 2012), bioactive and pharmaceutical compounds such as antioxidants, polyphenols, polyhydroxyalkanoates, carotenoids, galactomannans, among others (Acevedo et al., 2013; Mussatto, Ballesteros, Martins, \& Teixeira, 2011; Obruca, Benesova, Petrik, Kucera, \& Marova, 2014; Obruca, Benesova, Petrik, Oborna, et al., 2014; Obruca, Petrik, et al., 2014; Panusa et al., 2013; Petrik, Obruca, Benesova, \& Marova, 2014; Ramalakshmi, Rao, Takano-Ishikawa, \& Goto, 2009; Zuorro \& Lavecchia, 2011, 2012).

More recent applications for the reuse of waste oils have started to gain momentum in the asphalt industry (Azahar, Bujang, Jaya, Hainin, Mohamed, et al., 2016; Azahar, Bujang, Jaya, Hainin, Ngadi, et al., 2016; Maharaj, Harry, \& Mohamed, 2015; Man, Wang, Xu, \& Suo, 2016; Zargar, Ahmadinia, Ash, \& Karim, 2012). Asphalt binder, also referred to as bitumen, is a constituent of petroleum most widely used to pave roads, were found to harden and age during 
storage, mixing with rock constituents (quarry aggregates), transport and paving due to oxidation and loss of their oil fraction leading to cracking problems in roads after paving (Petersen, 2009). Desirable properties were usually restored using commercial rejuvenators rather than dumping the damaged asphalt paving mixture. Recently, natural oils, including waste cooking oil and recycled motor oil, have been studied as potential natural rejuvenators. It was found that 3-4\% of waste cooking compared to $20 \%$ recycled motor oil is required to restore the physical properties of the original asphalt binder (Zargar et al., 2012). These findings have helped highlight waste oils as rejuvenators that could potentially aid in reducing the use of virgin petroleum materials (asphalt) and natural resources (quarry aggregates) as well as dumping of damaged asphaltic material and oils in the environment. However, although WCO was found to be two to three times cheaper than virgin oils ( $\mathrm{Li} \&$ Wang, 2015), the heterogeneous nature of the oil and its diverse applications in the food industry and households were found to vary the physical properties of the aged or damaged asphalt binder to different extents (Sanli, Canakci, \& Alptekin, 2011).

Consequently, it is important to characterize the physicochemical properties of WCO and SCG subjected to different levels of oxidation, the major contributor to oil degradation, prior to its use as rejuvenators in aged asphalt mixtures. This will further help explore the potential of induced oxidation in modifying the physical properties of oils to desirable levels which may present a benefit in the customization of the physical properties of asphalt blends, especially when little research exists on this topic (Chehab \& Daniel, 2006; Daniel, Chehab, \& Kim, 2004).

The objectives of this study are to investigate the effect of oxidation on the physicochemical and rheological properties of Spent Coffee Grounds Oil (SCG) and Waste Cooking Oil (WCO) 
in order to evaluate their potential use as binder rejuvenators in reclaimed asphalt binders from aged and damaged pavements.

\section{Materials and Methods}

\subsection{Materials}

For the purpose of this study, various samples of spent coffee ground (SCG) were collected from coffee shops pertaining to four different international chains in Beirut, Lebanon. Similarly, samples of waste cooking oil (WCO) were collected from local restaurants around Beirut,

Lebanon. Hexane (purity $\geq 98 \%$ ), potassium iodide powder (purity $\geq 99 \%$ ), 2-propanol (purity $\geq 99.5 \%)$, sodium thiosulfate $(0.1 \mathrm{M})$, hydrochloric acid $(0.5 \mathrm{M})$, potassium hydroxide $(0.1 \mathrm{M})$ and chloroform (purity $\geq 99.4 \%$ ) were purchased from Sigma-Aldrich Corp (MO, US). Magnesium sulfate anhydrous (purity $\geq 99 \%$ ) and carbon tetrachloride (purity $\geq 99.5 \%$ ) were acquired from Uni-Chem (Guangzhou, China). Wij’s iodine solution (purity $\geq 99 \%$ ) was purchased from Fisher Scientific (Leics, UK). Toluene (purity $\geq 99.5 \%$ ) and acetic acid (purity $\geq 99.8 \%$ ) were purchased from VWR (PA, USA).

\subsection{Oil Extraction and Collection}

Upon receipt, SCG were tested for their moisture content, after which, they were dried for three hours at $105^{\circ} \mathrm{C}$ to remove residual moisture. Determination of oil content was performed using a Soxhlet apparatus where hexane has been used as solvent. Following the extraction, the hexane-oil mixture was dried over magnesium sulfate powder to remove any residual moisture after which the solvent was distilled out by rotary evaporation at $335 \mathrm{mbar}$ and $55^{\circ} \mathrm{C}$ and the oil samples were collected via reflux extraction.

On the other hand, WCO collected from different sources were mixed together in equal quantities and passed over magnesium sulfate powder prior to the oxidation process. 


\subsection{Oil Oxidation}

SCG oil and WCO were oxidized over $6,9,12,24$, and 48 hours at $135^{\circ} \mathrm{C}$. This process was performed by continuously bubbling air at a rate of 3L/hour into oil samples placed in $100 \mathrm{~mL}$ Erlenmeyer flasks under controlled heating over a ceramic hotplate.

\subsection{Oil Physicochemical Characterization}

SCG oil and WCO were initially characterized following official methods reported by the Association of Analytical Chemists (AOAC) and the American Oil Chemists' Society (AOCS). Peroxide Value (PV), Acid Value (AV), and Iodine Value (IV) were obtained according to methods AOAC 965.33, AOCS Cd 3d-63, and AOCS Cd 1-25, respectively. The titration for the above tests was performed using a 916 Ti-Touch (Metrohm, Ionenstrasse, Herisau, Switzerland) with five replicates. In order to follow the structural changes of the oil over the oxidation process, Fourier Transform Infrared Spectroscopy (FTIR) was performed in triplicates between 4,000 - $650 \mathrm{~cm}^{-1}$ using a Nicolet 4700 FT-IR Spectrometer (Thermo Fisher Scientific Inc., Waltham, MA, USA) with KBr plates, and the spectra analyzed using OMNIC data processing software.

The oils were physically characterized at $40^{\circ} \mathrm{C}$ and $100^{\circ} \mathrm{C}$ for their linear viscoelastic behavior. The linear viscoelastic range was determined through a strain control test at a frequency of $1 \mathrm{~Hz}$, with strain amplitude varying from 0.0125 to $12.5 \%$; viscosities were measured according to ASTM D2270-10E1; whereas, the storage and loss moduli were determined for the linear viscoelastic range through sinusoidal testing at $0.1 \%$ strain at frequencies ranging from 0.01 to $50 \mathrm{~Hz}$. The tests were conducted using a Discovery Series Hybrid Rheometer - DHR (TA-Instruments, New Castle, DE, USA), equipped with 25mm parallel plates, in duplicates as the standard error did not exceed 5\% between replicates. 


\section{Results and Discussion}

\subsection{Oil Extraction from SCG}

Measuring the initial moisture content of the received SCG revealed a value of 58\%, This latter is consistent with some data found in the literature (Kondamudi, Mohapatra et al. 2008, Vardon, Moser et al. 2013, Pichai and Krit 2015), however it is different from some reported values ranging from $12 \%$ to $40 \%$ (Nídia S Caetano et al., 2014; Nidia S. Caetano, Silva, \& Mata, 2012). This noticeable difference is probably due to the various brewing methods and extraction processes which usually utilize pressure during the preparation of coffee.

Soxhlet extraction yielded $14 \%$ by weight of oil which in a perfect agreement with earlier studies reporting an oil content ranging between $11 \%$ and $20 \%$ by weight depending on the type of coffee and solvent, with an average of 15\% (Abdullah \& Bulent Koc, 2013; Al-Hamamre et al., 2012; Nidia S. Caetano et al., 2012; Mussatto, Machado, et al., 2011).

\subsection{Oil Physicochemical Characterization}

The peroxide, acid, and iodine values of SCG oil and WCO immediately after reception, compared to values reported in the literature, along with fresh samples that did not undergo any processing are summarized in Table 1. The results show that at reception, SCG oil was less oxidized (6.73 meq peroxide/kg) than WCO (64.47 meq peroxide/ $\mathrm{kg}$ ) but more acidic, with a recorded $\mathrm{AV}$ of $10.92 \mathrm{mg} \mathrm{KOH} / \mathrm{g}$ as compared to $3.39 \mathrm{mg} \mathrm{KOH} / \mathrm{g}$ for the WCO. This is related to the higher processing and refining of WCO as well as its repeated use as frying oil in the food industry as compared to SCG oil. WCO is usually exposes to higher levels of oxidation mainly caused by contact with air (auto-oxidation) and water from food (hydrolytic oxidation). Moreover, the higher acidity in SCG oil is mainly attributed to the presence of free fatty acids (Nidia S. Caetano et al., 2012). 
According to the Food and Agriculture Organization of the United Nations (FAO) and CODEX (2001) the WCO used in the current study at reception is officially considered as waste oil, being non-compliant with the specified standards which denote the PV limit of 10 meq peroxide $/ \mathrm{kg}$ in refined vegetable oils. The results of fresh samples show how processing significantly alters the chemical properties of both types of oil. As for the changes observed throughout the induced oxidation, it can be noticed that as oxidation time increases, the acidity of both oils increases (Figure 1a). This is due to the gradual release of free fatty acids from triglycerides under high temperature by $\beta$ hydrogen elimination followed by hydrolysis (Fox \& Stachowiak, 2007). The opposite trend was observed for IV (Figure 1b), which is an indication of the level of saturation and the number of double bonds. Beyond 12 hours of oxidation, a significant decrease in the iodine value was observed for both oils. This is associated with the breaking of double bonds. A similar trend was observed by Paschke and Wheeler (1954) who reported a decrease in the IV for polymerized linseed oil at $300^{\circ} \mathrm{C}$ for a time ranging between 1.5 and 6 hours. Fox and Stachowiak (2007) stated that oils having greater levels of unsaturation are more susceptible to oxidation, making WCO - having a higher IV value than SCG throughout the entire oxidation process - more prone to degradation and thus physical alterations.

As for the peroxide value (Figure 1c), a maximum value of $13.35 \mathrm{meq}$ peroxide $/ \mathrm{kg}$ for SCG oil and 174.25 meq peroxide/kg for WCO were recorded after 6 hours of oxidation, followed by a constant decrease until a plateau was reached at $10 \mathrm{meq}$ peroxide/kg for both oils. The latter followed a typical trend where the peak value represents the maximum level of primary oxidation metabolites as hydro-peroxides, followed by their degradation into secondary metabolites as epoxides and high molecular weight compounds. It is these secondary metabolites 
that cause major physical changes in vegetable oils, especially observed in the increased viscosity (Fox \& Stachowiak, 2007).

FTIR spectra revealed the presence of O-H, C-H, and C=O shown at $3473 \mathrm{~cm}^{-1}, 2925 \mathrm{~cm}^{-1}$, and $1745 \mathrm{~cm}^{-1}$; respectively. Other vibrational bands showed the presence of amine and $\mathrm{C}-\mathrm{H}$ at $1465 \mathrm{~cm}^{-1}, 1162 \mathrm{~cm}^{-1}$, and $717 \mathrm{~cm}^{-1}$. Data collection over time showed no significant change in peaks in both SCG oil and WCO spectra as illustrated in Figure 2. However, the $\mathrm{C}=\mathrm{O}$ showed a linear increase which may be associated with the breaking of $\mathrm{C}=\mathrm{C}$ and introduction of oxygen upon induced oxidation.

In order to perceive the changes observed in the chemical tests, physical characterization of both oils was performed. Linear visco-elastic behavior was first determined at $0.1 \%$ strain as determined by the DHR tests. This value was thereafter used for the remaining physical tests to obtain representative results. Mainly, both SCG oil and WCO exhibited a Newtonian flow behavior regardless of the level of oxidation and temperature, as shown in Figure 3. This behavior was evident from plots of shear stress versus shear rate obtained from flow sweep tests which were performed during the determination of the viscosity. A linear relationship $\left(\mathrm{r}^{2}=0.999\right)$ is observed thus indicating that the viscosity is independent of the shear rate. This shows that despite induced oxidation for long periods of time (up to 48 hours), the behavior of the flow does not change.

Values of viscosity of both SCG oil and $\mathrm{WCO}$ at $40^{\circ} \mathrm{C}$ and $100^{\circ} \mathrm{C}$ are summarized in Table 2 and show the significant increase after 12 hours, caused by the induced oxidation. Viscosities were reported to increase by more than 2 folds after 24 hours of oxidation and exceeded 10 folds after 48 hours. This increase in the oils' viscosities could be related to the changes in the physical 
structure of the oil molecules as well as induced polymerization caused by extensive oxidation over time (Santos, Santos, \& Souza, 2005). This is mainly due to the formation of high molecular weight compounds which result from cyclisation and polymerization at high temperatures which is evident from the decrease in peak values of PV after 6 hours of oxidation, indicating the final stages of oxidation (Fox \& Stachowiak, 2007).

The correlation between PV of both oils and their subsequent viscosities is represented in Figure 4. It can be noticed that the PV peaks at a low viscosity but after that a constant decrease in PV is observed with increasing viscosity. Another factor which may be contributing to the increased viscosities is the breaking of double bonds $(\mathrm{C}=\mathrm{C})$, marked by the decrease in IV, leading to the gradual formation of more saturated fatty acid chains having a higher viscosity. Viscosities are also noticed to decrease with increasing temperatures. This is due to the dependence of the viscosities of liquid foods on their temperature and composition as stated by (Rao, 1977). As temperature increases, intermolecular forces are weakened which in turn increase molecular thermal movement and eases flow within the oil, thus reducing the viscosity. Such decrease in viscosity versus increasing temperatures has been reported in several vegetable oils (Diamante \& Lan, 2014; Esteban, Riba, Baquero, Rius, \& Puig, 2012; Fasina \& Colley, 2008).

Additionally, statistical analysis showed no significant difference between the viscosities of SCG oil and $\mathrm{WCO}$ at $100^{\circ} \mathrm{C}$ but not at $40{ }^{\circ} \mathrm{C}$. This shows that at relatively low temperatures, bonds between the oil molecules are stronger unlike at high temperatures. Hence it can be concluded that regardless of the physical changes witnessed within the two different oils, the performances of SCG oil and WCO at high temperatures, close to the mixing temperatures of asphalt binders, are considered similar. 
Further insight of the linear viscoelastic behavior throughout the oxidation process of the oils can be obtained through the analysis of the storage $\left(\mathrm{G}^{\prime}\right)$ and loss $\left(\mathrm{G}^{\prime \prime}\right)$ moduli representing the elastic and viscous components of the response, respectively. The tangent of the phase angle, $\tan \delta$, which is equivalent to the ratio of loss to storage modulus $\left(\mathrm{G}^{\prime \prime} / \mathrm{G}^{\prime}\right)$ is plotted as a function of oscillatory frequency in Figure 5. Results show that at low frequencies, both SCG and WCO oils exhibit a predominantly viscous behavior especially for highly oxidized oils. Elastic behavior becomes more evident at higher angular frequencies (Figure 6).

\section{Conclusions}

The main goal of this study was to explore the effect of longer oxidation periods on the physicochemical properties of the waste and extracted oils. Accordingly, longer oxidation times were found to increase the viscoelasticity of the waste oils. Such modification in the physicochemical properties present new potential for using the waste oils as sustainable rejuvenators for reclaimed aged or damaged asphalt binders. Moreover, controlling the oxidation process and duration can be utilized to customize the viscosities of oils to obtain "a la carte" properties depending on the desired modifications based on the characteristics of the reclaimed binder. Ultimately, this will contribute to mitigating the disposal of both asphaltic and food wastes. This is especially true since the oils possess desirable properties as being convenient, having a high flash point for better safety, reported to improve the physical properties of aged asphalt and being wastes of renewable feedstock.

\section{Acknowledgments}

This study was funded by the University Research Board (URB) at the American University of Beirut (AUB). The authors would like to thank all the local restaurants and coffee shops that provided the oil/coffee for this study. 


\section{References}

Abdullah, M., \& Bulent Koc, A. (2013). Oil removal from waste coffee grounds using two-phase solvent extraction enhanced with ultrasonication. Renewable Energy, 50(0), 965-970. doi:http://dx.doi.org/10.1016/j.renene.2012.08.073

Acevedo, F., Rubilar, M., Scheuermann, E., Cancino, B., Uquiche, E., Garces, M., ... Shene, C. (2013). Spent Coffee Grounds as a Renewable Source of Bioactive Compounds. Journal of Biobased Materials and Bioenergy, 7(3), 420-428. doi:10.1166/jbmb.2013.1369

Adi, A. J., \& Noor, Z. M. (2009). Waste recycling: Utilization of coffee grounds and kitchen waste in vermicomposting. Bioresource Technology, 100(2), 1027-1030. doi:10.1016/j.biortech.2008.07.024

Al-Hamamre, Z., Foerster, S., Hartmann, F., Kröger, M., \& Kaltschmitt, M. (2012). Oil extracted from spent coffee grounds as a renewable source for fatty acid methyl ester manufacturing. Fuel, 96(0), 70-76. doi:http://dx.doi.org/10.1016/j.fuel.2012.01.023

Azahar, W. N. A. W., Bujang, M., Jaya, R. P., Hainin, M. R., Mohamed, A., Ngadi, N., \& Jayanti, D. S. (2016). The Potential of Waste Cooking Oil as Bio-Asphalt for Alternative Binder - an Overview. Jurnal Teknologi, 78(4), 111-116.

Azahar, W. N. A. W., Bujang, M., Jaya, R. P., Hainin, M. R., Ngadi, N., Abdullah, M. E., \& Mohamed, A. A. (2016). A Review on Application of Waste Cooking Oil as Rejuvenator in Porous Asphalt Mixture. Jurnal Teknologi, 78(4), 105-109.

Caetano, N. S., Silva, V. F., Melo, A. C., Martins, A. A., \& Mata, T. M. (2014). Spent coffee grounds for biodiesel production and other applications. Clean Technologies and Environmental Policy, 16(7), 1423-1430.

Caetano, N. S., Silva, V. F. M., \& Mata, T. M. (2012). Valorization of coffee grounds for biodiesel production. Chemical engineering transactions, 26, 267-272.

Chehab, G. R., \& Daniel, J. S. (2006). Evaluating recycled asphalt pavement mixtures with mechanistic-empirical pavement design guide Level 3 analysis. Bituminous Materials and Nonbituminous Components of Bituminous Paving Mixtures 2006(1962), 90-100.

CODEX. (2001). Codex Standard for Named Vegetable Oils (CODEX-STAN 210 - 1999) Codex Standards for Fats and Oils from Vegetable Sources. Rome, Italy: CODEX Alimentarius, Food and Agriculture Organization of the United Nations, World Health Organization

Daniel, J. S., Chehab, G. R., \& Kim, Y. R. (2004). Issues affecting measurement of the complex modulus of asphalt concrete. Journal of Materials in Civil Engineering, 16(5), 469-476. doi:10.1061/(Asce)0899-1561(2004)16:5(469) 
Diamante, L. M., \& Lan, T. (2014). Absolute viscosities of vegetable oils at different temperatures and shear rate range of 64.5 to $4835 \mathrm{~s}-1$. Journal of Food Processing, 2014.

Dinsdale, R. M., Hawkes, F. R., \& Hawkes, D. L. (1996). The mesophilic and thermophilic anaerobic digestion of coffee waste containing coffee grounds. Water Research, 30(2), 371-377. doi:http://dx.doi.org/10.1016/0043-1354(95)00157-3

Esteban, B., Riba, J.-R., Baquero, G., Rius, A., \& Puig, R. (2012). Temperature dependence of density and viscosity of vegetable oils. Biomass and bioenergy, 42, 164-171.

Fasina, O., \& Colley, Z. (2008). Viscosity and specific heat of vegetable oils as a function of temperature: $35 \mathrm{C}$ to $180 \mathrm{C}$. International Journal of Food Properties, 11(4), 738-746.

Fox, N., \& Stachowiak, G. (2007). Vegetable oil-based lubricants - a review of oxidation. Tribology international, 40(7), 1035-1046.

Franca, A. S., Oliveira, L. S., Mendonca, J. C. F., \& Silva, X. A. (2005). Physical and chemical attributes of defective crude and roasted coffee beans. Food Chemistry, 90(1-2), 89-94. doi:10.1016/j.foodchem.2004.03.028

Franca, A. S., Oliveira, L. S., Mendonça, J. C. F., \& Silva, X. A. (2005). Physical and chemical attributes of defective crude and roasted coffee beans. Food Chemistry, 90(1-2), 89-94. doi:http://dx.doi.org/10.1016/j.foodchem.2004.03.028

Givens, D. I., \& Barber, W. P. (1986). Invivo Evaluation of Spent Coffee Grounds as a Ruminant Feed. Agricultural Wastes, 18(1), 69-72. doi:Doi 10.1016/0141-4607(86)90108-3

ICO. (2015). Annual Review 2013-2014. Retrieved from London, UK:

Kabir, I., Yacob, M. R., \& Radam, A. (2014). Households' Awareness, Attitudes and Practices Regarding Waste Cooking Oil Recycling in Petaling, Malaysia. IOSR-JESTFT, 8(10), 4551.

Kante, K., Nieto-Delgado, C., Rangel-Mendez, J. R., \& Bandosz, T. J. (2012). Spent coffeebased activated carbon: specific surface features and their importance for $\mathrm{H} 2 \mathrm{~S}$ separation process. Journal of Hazardous Materials, 201, 141-147.

Khan, N. A., \& Brown, J. B. (1953). The Composition of Coffee Oil and Its Component Fatty Acids. Journal of the American Oil Chemists Society, 30(12), 606-609. doi:Doi 10.1007/Bf02640975 
Kondamudi, N., Mohapatra, S. K., \& Misra, M. (2008). Spent Coffee Grounds as a Versatile Source of Green Energy. Journal of Agricultural and Food Chemistry, 56(24), 11757 11760. doi:10.1021/jf802487s

Kulkarni, M. G., \& Dalai, A. K. (2006). Waste cooking oil-an economical source for biodiesel: A review. Industrial \& Engineering Chemistry Research, 45(9), 2901-2913. doi:10.1021/ie0510526

Lavecchia, R., Pugliese, A., \& Zuorro, A. (2010). Removal of lead from aqueous solutions by spent tea leaves. Cisap4: 4th International Conference on Safety \& Environment in Process Industry, 19, 73-78. doi:10.3303/Cet1019013

Li, W. M., \& Wang, X. B. (2015). Bio-lubricants Derived from Waste Cooking Oil with Improved Oxidation Stability and Low-temperature Properties. Journal of Oleo Science, 64(4), 367-374. doi:10.5650/jos.ess 14235

Liu, K., \& Price, G. (2011). Evaluation of three composting systems for the management of spent coffee grounds. Bioresource Technology, 102(17), 7966-7974.

Maharaj, R., Harry, V., \& Mohamed, N. (2015). The Rheological Properties of Trinidad Asphaltic Materials Blended With Waste Cooking Oil. Progress in Rubber Plastics and Recycling Technology, 31(4), 265-279.

Man, Q., Wang, J., Xu, S. F., \& Suo, Z. (2016). Performance evaluation of the recycling asphalt binder regenerated with vegetable oil. Civil Engineering and Urban Planning Iv, 985987.

Mussatto, S. I., Ballesteros, L. F., Martins, S., \& Teixeira, J. A. (2011). Extraction of antioxidant phenolic compounds from spent coffee grounds. Separation and Purification Technology, 83, 173-179.

Mussatto, S. I., Machado, E. M., Carneiro, L. M., \& Teixeira, J. A. (2012). Sugars metabolism and ethanol production by different yeast strains from coffee industry wastes hydrolysates. Applied energy, 92, 763-768.

Mussatto, S. I., Machado, E. M., Martins, S., \& Teixeira, J. A. (2011). Production, composition, and application of coffee and its industrial residues. Food and Bioprocess Technology, $4(5), 661$.

Obruca, S., Benesova, P., Petrik, S., Kucera, D., \& Marova, I. (2014). Biotechnological conversion of spent coffee grounds into polyhydroxyalkanoates. New Biotechnology, 31, S39-S40. doi:10.1016/j.nbt.2014.05.1701 
Obruca, S., Benesova, P., Petrik, S., Oborna, J., Prikryl, R., \& Marova, I. (2014). Production of polyhydroxyalkanoates using hydrolysate of spent coffee grounds. Process Biochemistry, 49(9), 1409-1414. doi:10.1016/j.procbio.2014.05.013

Obruca, S., Petrik, S., Benesova, P., Svoboda, Z., Eremka, L., \& Marova, I. (2014). Utilization of oil extracted from spent coffee grounds for sustainable production of polyhydroxyalkanoates. Applied Microbiology and Biotechnology, 98(13), 5883-5890. doi:10.1007/s00253-014-5653-3

Panusa, A., Zuorro, A., Lavecchia, R., Marrosu, G., \& Petrucci, R. (2013). Recovery of Natural Antioxidants from Spent Coffee Grounds. Journal of Agricultural and Food Chemistry, 61(17), 4162-4168. doi:10.1021/jf4005719

Paschke, R., \& Wheeler, D. (1954). Inter-and intramolecular polymerization in heat-bodied linseed oil. Journal of the American Oil Chemists Society, 31(5), 208-211.

Petersen, J. C. (2009). A review of the fundamentals of asphalt oxidation: chemical, physicochemical, physical property, and durability relationships. Transportation Research E-Circular(E-C140).

Petrik, S., Obruca, S., Benesova, P., \& Marova, I. (2014). Bioconversion of spent coffee grounds into carotenoids and other valuable metabolites by selected red yeast strains. Biochemical Engineering Journal, 90, 307-315. doi:10.1016/j.bej.2014.06.025

Phimsen, S., Kiatkittipong, W., Yamada, H., Tagawa, T., Kiatkittipong, K., Laosiripojana, N., \& Assabumrungrat, S. (2016). Oil extracted from spent coffee grounds for bio-hydrotreated diesel production. Energy Conversion and Management, 126, 1028-1036. doi:10.1016/j.enconman.2016.08.085

Ramalakshmi, K., Rao, L. J. M., Takano-Ishikawa, Y., \& Goto, M. (2009). Bioactivities of lowgrade green coffee and spent coffee in different in vitro model systems. Food Chemistry, 115(1), 79-85. doi:10.1016/j.foodchem.2008.11.063

Rao, M. A. (1977). Rheology of Liquid Foods - A Review. Journal of Texture Studies, 8(2), 135168.

Sanli, H., Canakci, M., \& Alptekin, E. (2011). Characterization of waste frying oils obtained from different facilities. Paper presented at the World Renewable Energy CongressSweden; 8-13 May; 2011; Linköping; Sweden.

Santos, J. C. O., Santos, I. M. G., \& Souza, A. G. (2005). Effect of heating and cooling on rheological parameters of edible vegetable oils. Journal of Food Engineering, 67(4), 401405. doi:10.1016/j.jfoodeng.2004.05.007 
Vardon, D. R., Moser, B. R., Zheng, W., Witkin, K., Evangelista, R. L., Strathmann, T. J., . . . Sharma, B. K. (2013). Complete Utilization of Spent Coffee Grounds To Produce Biodiesel, Bio-Oil, and Biochar. Acs Sustainable Chemistry \& Engineering, 1(10), 12861294. doi: $10.1021 / \mathrm{sc} 400145 \mathrm{w}$

Wen, Z., Yu, X., Tu, S.-T., Yan, J., \& Dahlquist, E. (2010). Biodiesel production from waste cooking oil catalyzed by $\mathrm{TiO} 2-\mathrm{MgO}$ mixed oxides. Bioresource Technology, 101(24), 9570-9576.

Yaakob, Z., Mohammad, M., Alherbawi, M., Alam, Z., \& Sopian, K. (2013). Overview of the production of biodiesel from Waste cooking oil. Renewable \& Sustainable Energy Reviews, 18, 184-193. doi:10.1016/j.rser.2012.10.016

Zargar, M., Ahmadinia, E., Ash, H., \& Karim, M. R. (2012). Investigation of the possibility of using waste cooking oil as a rejuvenating agent for aged bitumen. Journal of Hazardous Materials, 233, 254-258. doi:10.1016/j.jhazmat.2012.06.021

Zuorro, A., \& Lavecchia, R. (2011). Polyphenols and energy recovery from spent coffee grounds. Pres 2011: 14th International Conference on Process Integration, Modelling and Optimisation for Energy Saving and Pollution Reduction, Pts 1 and 2, 25, 285-290. doi:10.3303/Cet1 125048

Zuorro, A., \& Lavecchia, R. (2012). Spent coffee grounds as a valuable source of phenolic compounds and bioenergy. Journal of Cleaner Production, 34, 49-56.

doi:10.1016/j.jclepro.2011.12.003 


\section{List of Tables}

Table 1 Peroxide value, acid value and iodine value for waste cooking oil and spent coffee ground oil extracts

Table 2 Viscosities of SCG oil and WCO

\section{List of Figures}

Figure 1 a) Acid Values (AV); b) Iodine Values (IV), and c) Peroxide Values (PV) for SCG oil $(\mathbf{\Delta})$ and $\mathrm{WCO}(\boldsymbol{\square})$

Figure 2 FTIR spectra of oxidized a) SCG oil and b) WCO

Figure 3 Stress-strain curves for SCG oil oxidized for 6 hours $(\boldsymbol{\Delta})$ and 48 hours $(\Delta)$ and WCO oxidized for 6 hours ( $\square$ ) and 48 hours ( $\square$ ) tested at a) $40^{\circ} \mathrm{C}$ and b) $100^{\circ} \mathrm{C}$

Figure 4 Peroxide value of oxidized SCG oil ( $\boldsymbol{\Delta})$ and WCO ( $\boldsymbol{\Xi})$ as a function of viscosity tested at $40^{\circ} \mathrm{C}$

Figure 5 Tan $\delta$ as a function of frequency for a) SCG oil and b) WCO

Figure 6 Storage modulus as a function of frequency for the oxidized oils a) SCG oil and b)

WCO 
Table 1 Peroxide value, acid value and iodine value for waste cooking oil and spent coffee ground oil extracts

\begin{tabular}{|c|c|c|c|}
\hline \multicolumn{4}{|c|}{ Waste cooking oil } \\
\hline & New Cooking Oil & As received & Reported elsewhere \\
\hline $\begin{array}{c}\text { PV } \\
(\text { meg peroxide/kg) }\end{array}$ & 5.17 & 64.47 & $50.61^{1}$ \\
\hline $\begin{array}{c}\mathbf{A V} \\
(\mathrm{mgKOH} / \mathrm{g})\end{array}$ & 0.13 & 3.39 & $3.60^{31}$ \\
\hline $\begin{array}{c}\mathbf{I V} \\
\left(\mathrm{gI}_{2} / 100 \mathrm{~g}\right)\end{array}$ & 140.91 & 117.34 & $109.19^{1,2}$ \\
\hline \multicolumn{4}{|c|}{ Oil extract / Coffee grounds } \\
\hline $\begin{array}{c}\mathbf{P V} \\
(\mathrm{meg} \mathrm{peroxide/kg)}\end{array}$ & Fresh Roasted Beans & As received & Reported elsewhere \\
\hline $\begin{array}{c}\mathbf{A V} \\
(\mathrm{mgKOH} / \mathrm{g})\end{array}$ & 0.57 & 6.73 & $5.2^{3}$ \\
\hline $\begin{array}{c}\text { IV } \\
(\mathrm{gI} / 100 \mathrm{~g})\end{array}$ & 5.06 & 10.92 & $7.1^{4}$ \\
\hline
\end{tabular}

${ }^{1}$ Sanli et al. (2011); ${ }^{2}$ Wen, Yu, Tu, Yan, and Dahlquist (2010); ${ }^{3}$ Khan and Brown (1953); ${ }^{4}$ Obruca, Benesova, Petrik, Oborna, et al. (2014);

Table 2 Viscosities of SCG oil and WCO

\begin{tabular}{|c|c|c|c|c|}
\hline \multirow{2}{*}{$\begin{array}{c}\text { Oxidation } \\
\text { Time (hr) }\end{array}$} & \multicolumn{4}{|c|}{ Viscosity (Pa.s) } \\
\cline { 2 - 5 } & \multicolumn{2}{|c|}{ SCG Oil } & $\mathbf{4 0}^{\circ} \mathbf{C}$ & $\mathbf{1 0 0}^{\circ} \mathbf{C}$ \\
\cline { 2 - 5 } & $\mathbf{4 0}^{\circ} \mathbf{C}$ & $\mathbf{1 0 0}^{\circ} \mathbf{C}$ & $0.0375^{\mathrm{a}^{*}}$ & $0.0079^{\mathrm{a}^{*}}$ \\
\hline 0 & $0.0449^{\mathrm{a}}$ & $0.0082^{\mathrm{a}}$ & $0.1185^{\mathrm{a}}$ & $0.0174^{\mathrm{b}}$ \\
\hline 6 & $0.0717^{\mathrm{a}}$ & $0.0115^{\mathrm{a}, \mathrm{b}}$ & $0.1200^{\mathrm{a}}$ & $0.0202^{\mathrm{b}}$ \\
\hline 12 & $0.1199^{\mathrm{a}, \mathrm{b}}$ & $0.0161^{\mathrm{b}}$ & $0.3023^{\mathrm{a}}$ & $0.0352^{\mathrm{c}}$ \\
\hline 24 & $0.2039^{\mathrm{b}}$ & $0.0236^{\mathrm{c}}$ & $3.5545^{\mathrm{b}}$ & $0.2523^{\mathrm{d}}$ \\
\hline 48 & $1.7144^{\mathrm{c}}$ & $0.1066^{\mathrm{d}}$ & \multicolumn{2}{|c}{} \\
\hline
\end{tabular}

Different letters indicate significant differences between groups per column $(P<0.05)(A N O V A$, Tuckey's HSD). *Compared to 0.0367Pa.s at $40^{\circ} \mathrm{C}$ and 0.0085Pa.s at $100^{\circ} \mathrm{C}$ (Li \& Wang, 2015). 

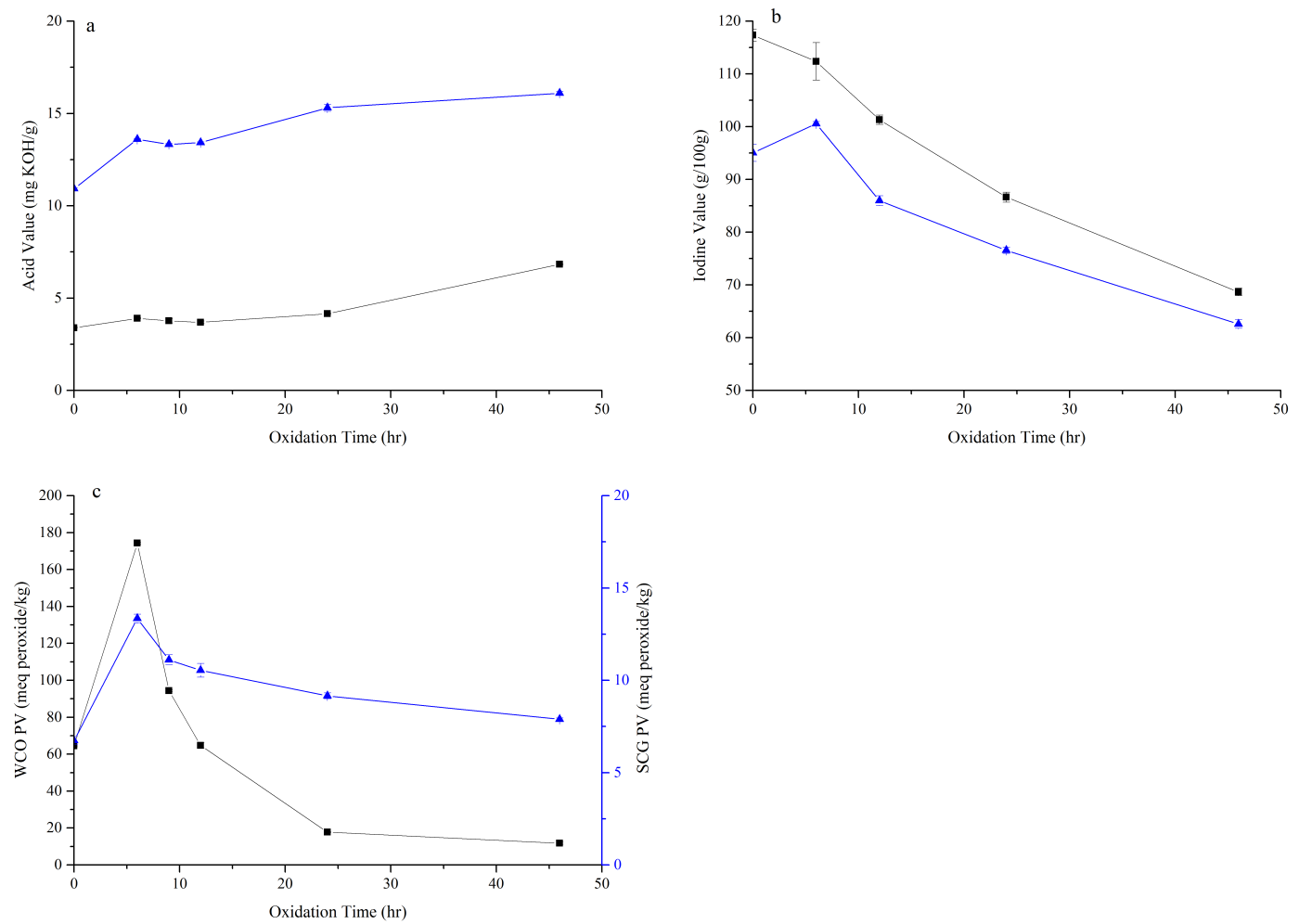

Figure 1 a) Acid Values (AV); b) Iodine Values (IV), and c) Peroxide Values (PV) for SCG oil $(\mathbf{\Delta})$ and $\mathrm{WCO}(\boldsymbol{\square})$ 

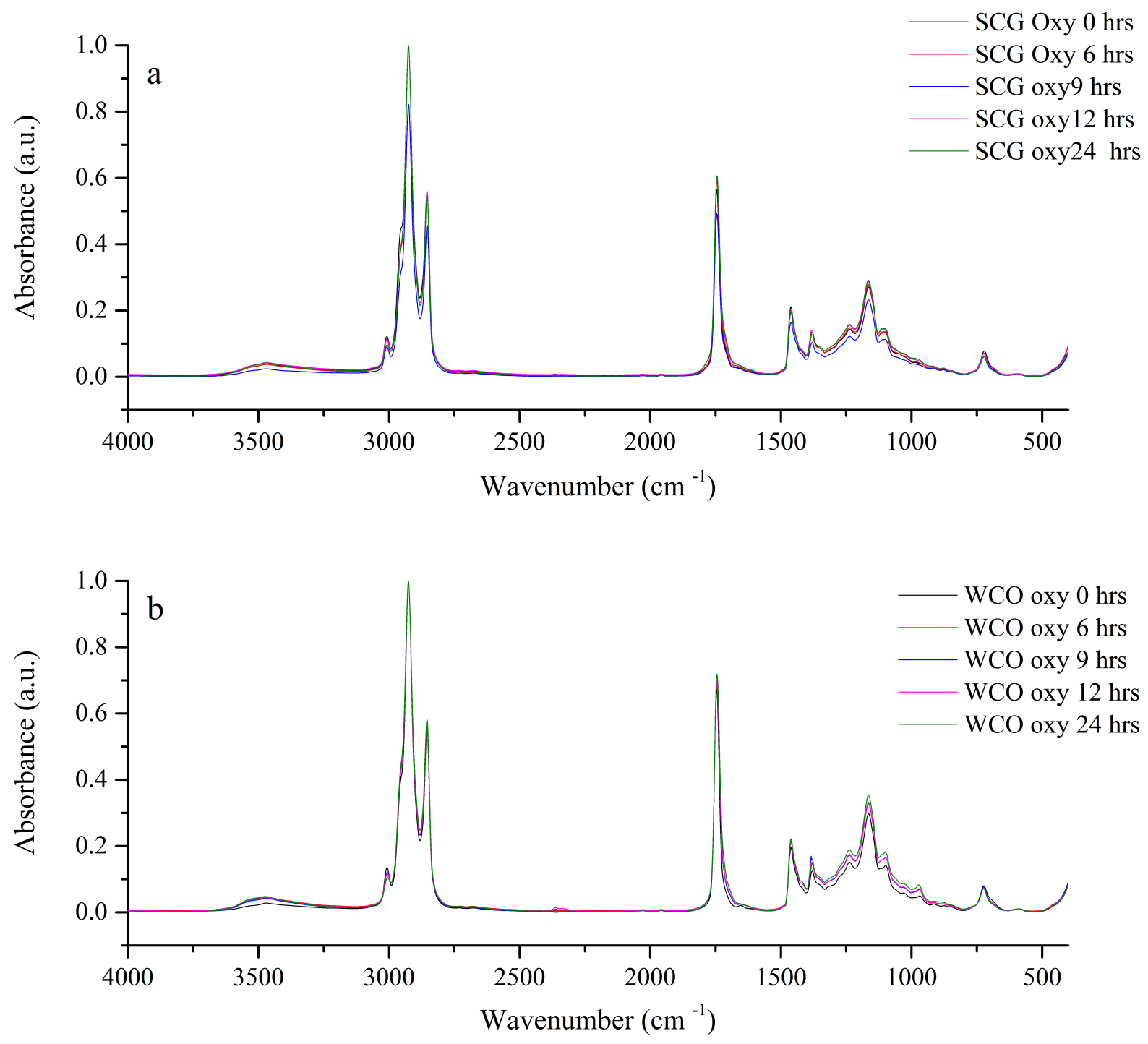

Figure 2 FTIR spectra of oxidized a) SCG oil and b) WCO 

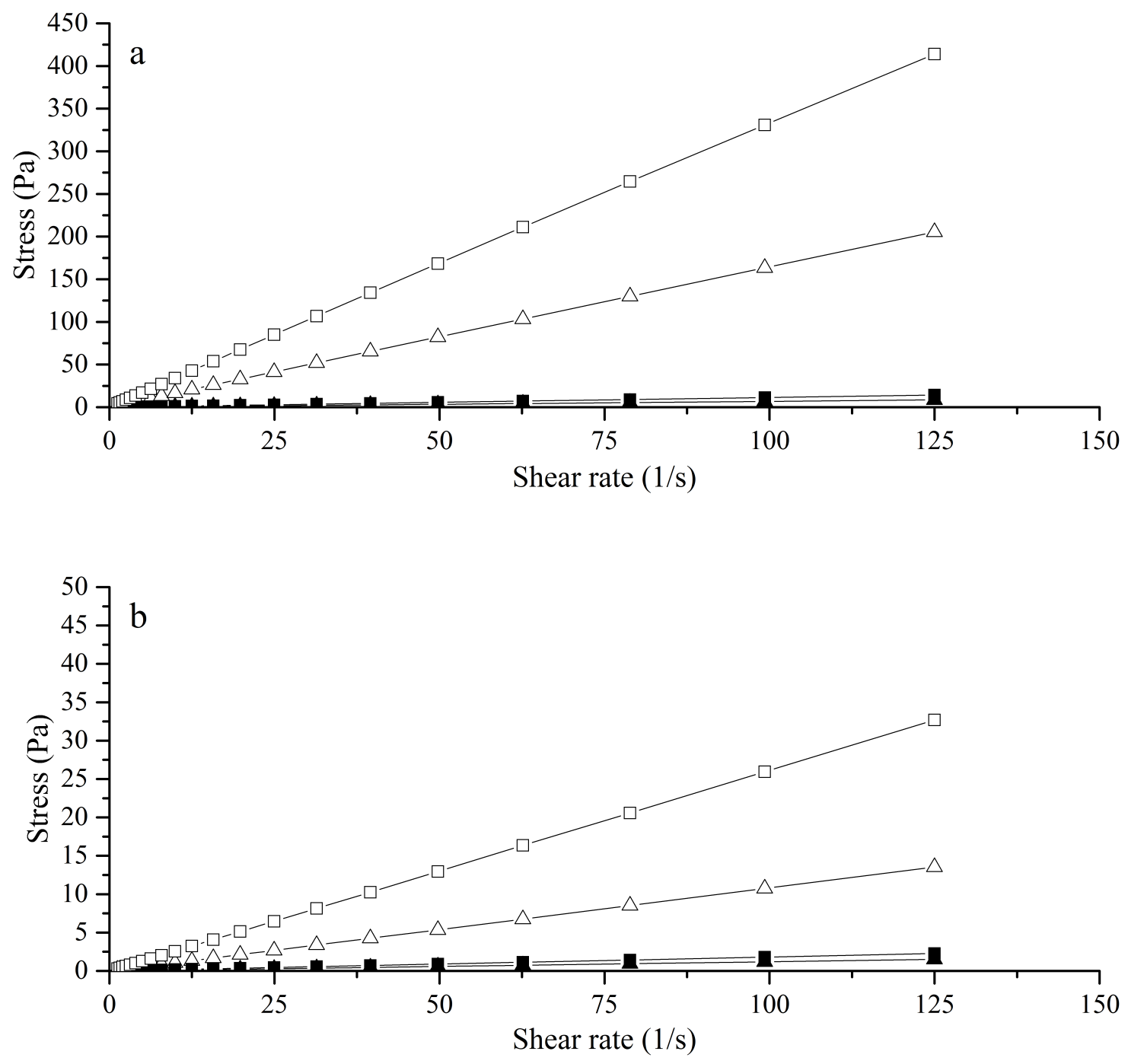

Figure 3 Stress-strain curves for SCG oil oxidized for 6 hours ( $(\mathbf{A})$ and 48 hours $(\Delta)$ and WCO oxidized for 6 hours (-) and 48 hours ( $\square$ ) tested at a) $40^{\circ} \mathrm{C}$ and b) $100^{\circ} \mathrm{C}$ 

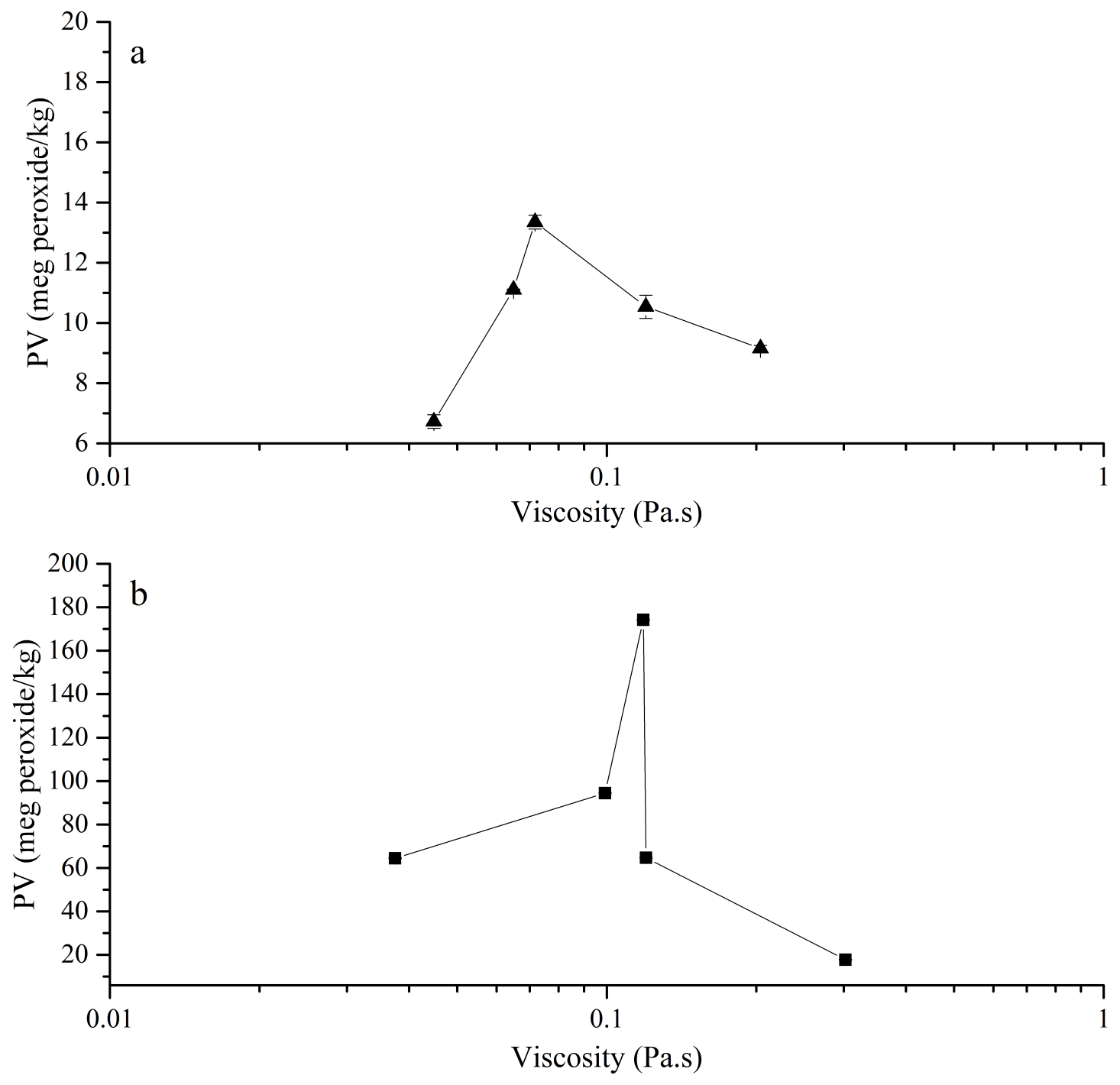

Figure 4 Peroxide value of oxidized SCG oil ( $\boldsymbol{\Delta})$ and WCO ( $\boldsymbol{\square})$ as a function of viscosity tested at $40^{\circ} \mathrm{C}$ 

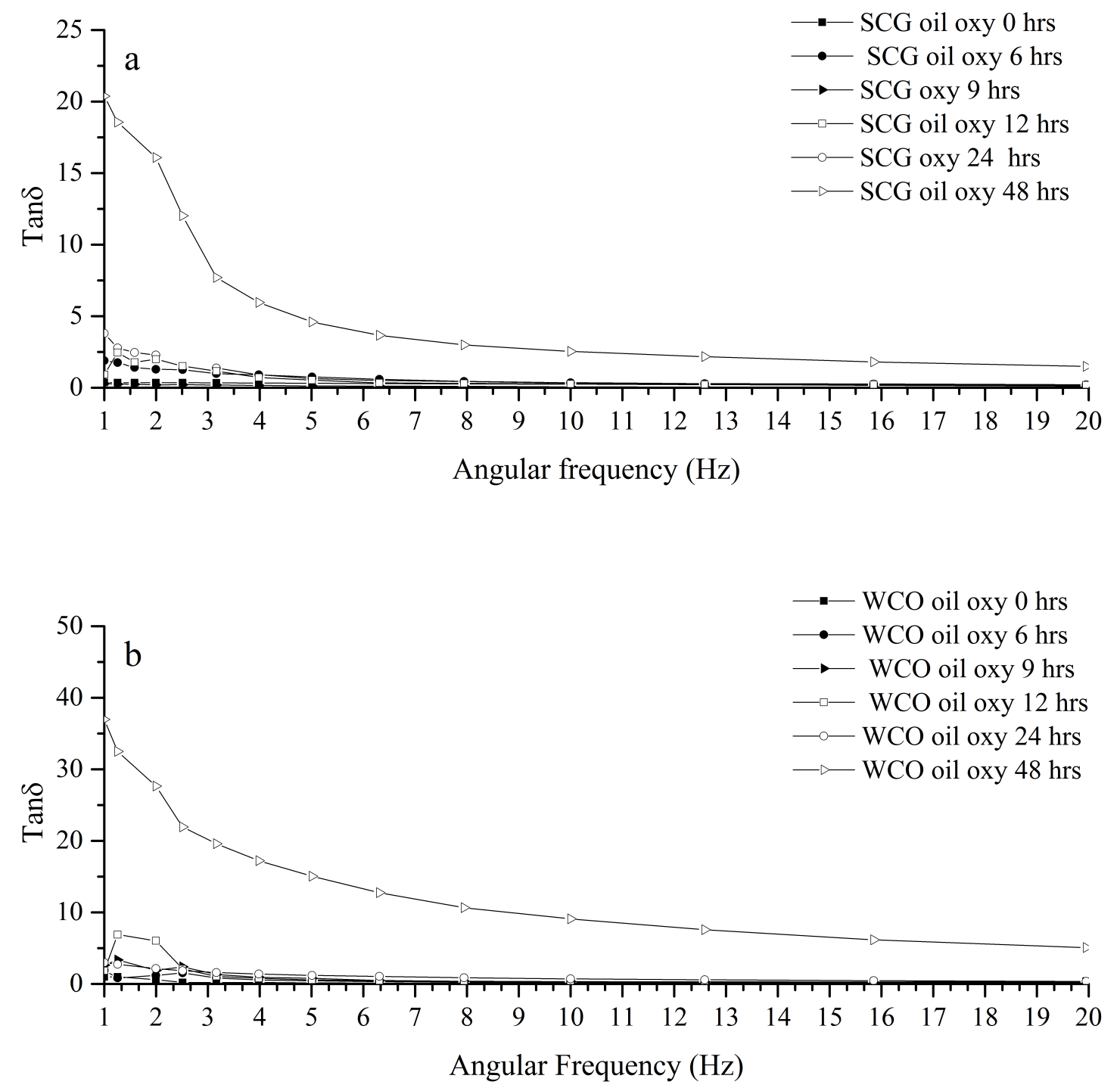

Figure 5 Tan $\delta$ as a function of frequency for a) SCG oil and b) WCO 

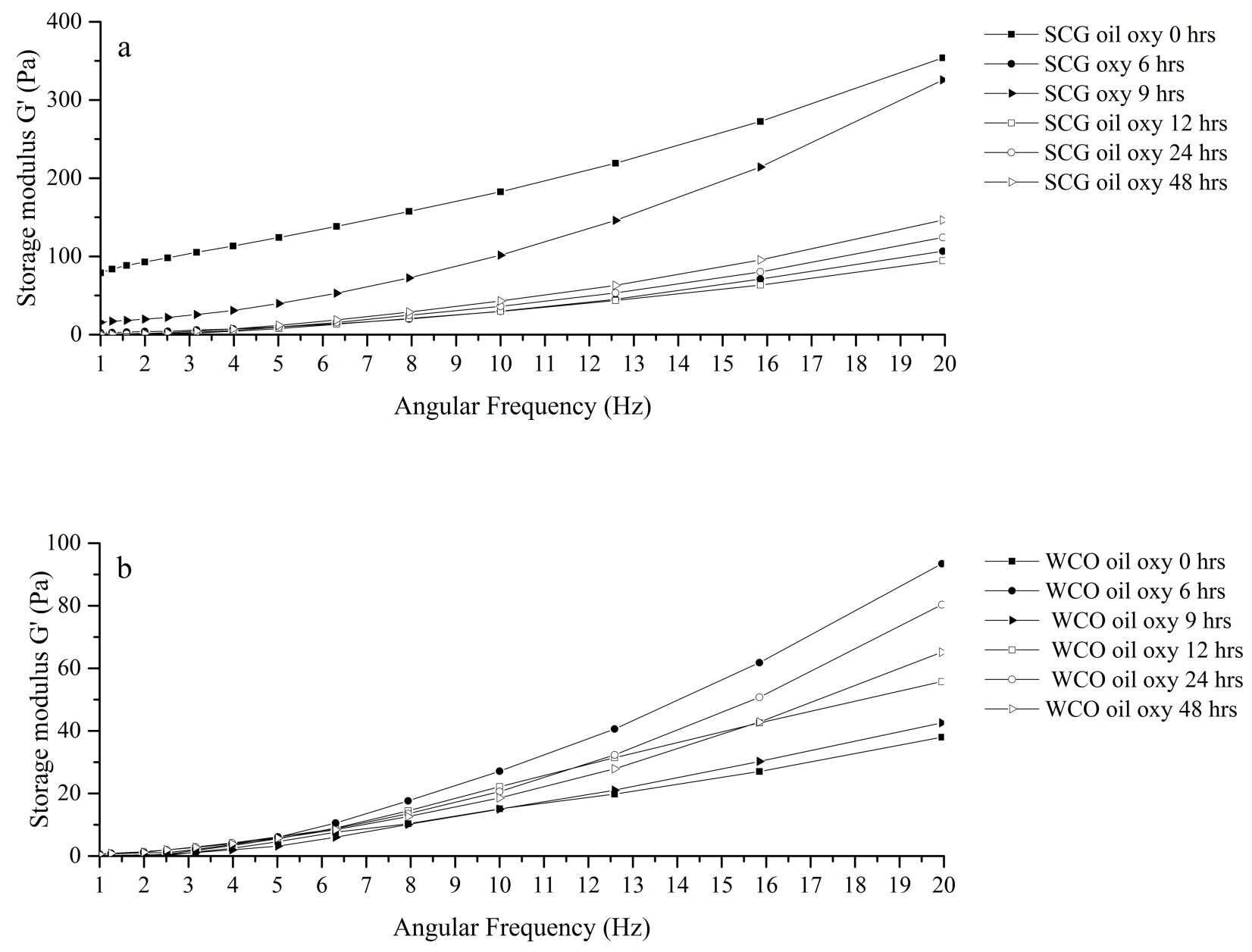

Figure 6 Storage modulus as a function of frequency for the oxidized oils a) SCG oil and b) WCO 